
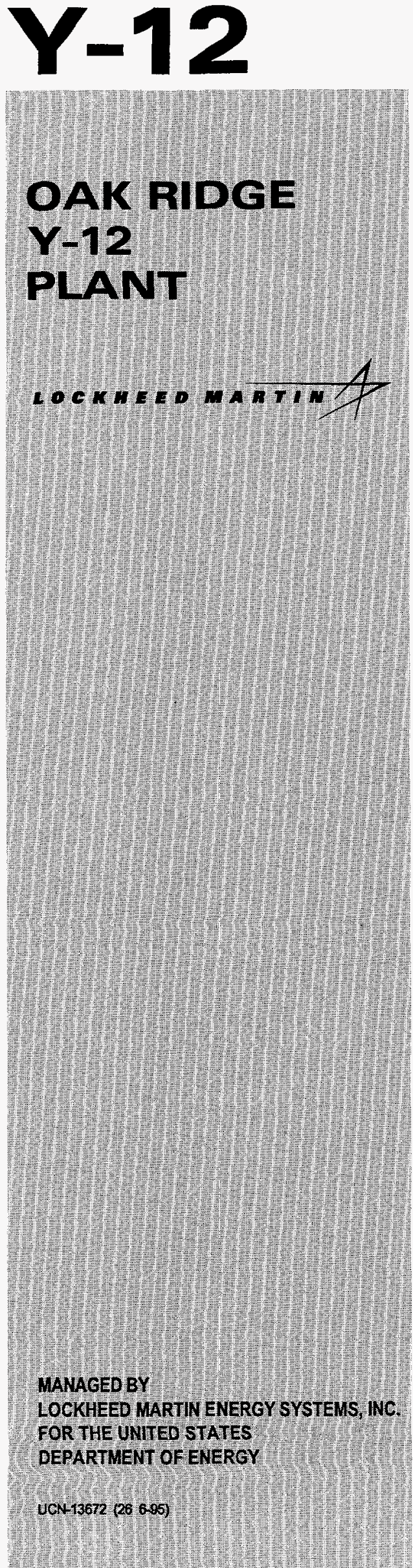

\author{
RECEIVED \\ JAN $O 41995$ \\ OSTI
}

\section{EXAMINATION OF FRIT VENT FROM SIXTY-WATT HEAT SOURCE SIMULANT FUELED \\ CLAD VENT SET}

\author{
G. B. Ulrich
}

Y-12 Development Division

November 1995

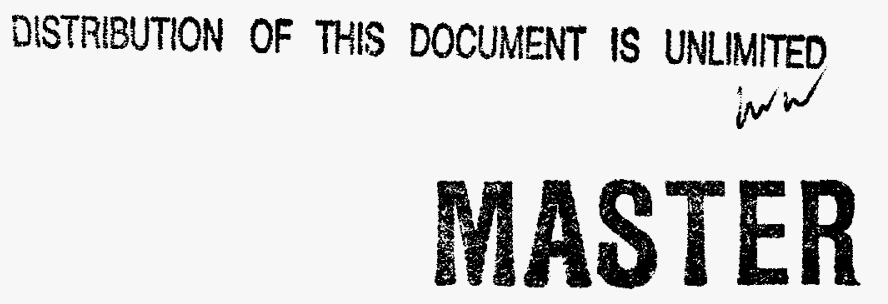




\section{DISCLAIMER}

This report was prepared as an account of work sponsored by an agency of the United States Government. Neither the United States Government nor any agency thereof, nor any of their employees, makes any warranty, express or implied, or assumes any legal liability or responsibility for the accuracy, completeness, or usefulness of any information, apparatus, product, or process disclosed, or represents that its use would not infringe privately owned rights. Reference herein to any specific commercial product, process, or service by trade name, trademark, manufacturer, or otherwise, does not necessarily constitute or imply its endorsement, recommendation, or favoring by the United States Government or any agency thereof. The views and opinions of authors expressed herein do not necessarily state or reflect those of the United States Government or any agency thereof. 


\title{
EXAMINATION OF FRIT VENT FROM SIXTY WATT HEAT SOURCE SIMULANT FUELED CLAD VENT SET
}

\author{
G. B. Ulrich \\ Process Metallurgy \\ Development Organization
}

November 1995

Prepared by the

Oak Ridge Y-12 Plant

P.O. Box 2009, Oak Ridge, Tennessee 37831-8169

managed by

LOCKHEED MARTIN ENERGY SYSTEMS, INC.

for the

U.S. DEPARTMENT of ENERGY

under contract DE-AC05-84OR21400 


\section{DISCLAMERR}

Portions of this document may be illegible in electronic image products. Images are produced from the best available original document. 


\section{CONTENTS}

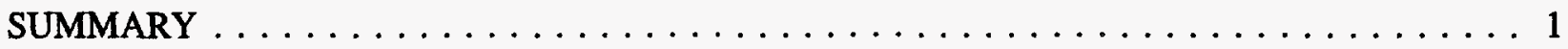

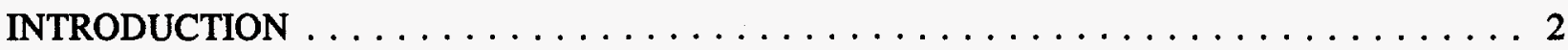

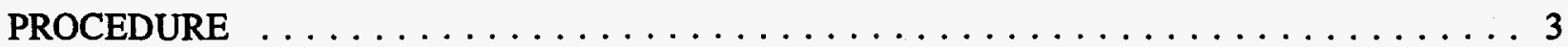

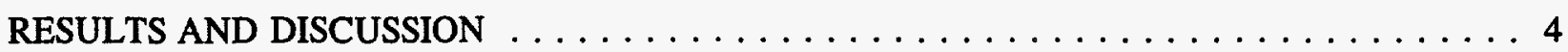

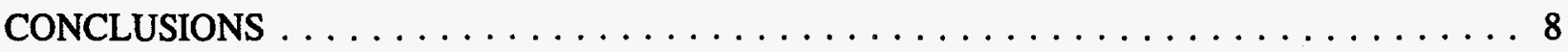




\section{FIGURES}

Figure

Page

1 Vent hole region of SC6029 after HIP and hole-drilling operations . . . . . 5 5

2 Left of vent hole region shown in Fig. $1 \ldots \ldots \ldots \ldots \ldots$

3 Vent hole region showing EDM artifacts $\ldots \ldots \ldots \ldots \ldots \ldots$

$4 \quad$ Frit vent subassembly showing good particle-to-particle and particle-to-foil component bonding . . . . . . . . . . . . 6

$5 \quad$ Higher-magnification view of Fig. 4 with frit vent backing disc at top, backing disc hole at right, and cover disc at the very bottom (as polished, $400 \mathrm{x}) \ldots \ldots \ldots \ldots \ldots \ldots \ldots$

6 Decontamination cover-to-cup and frit vent-to-cup weld Regions (etched 50x) . . . . . . . . . . . . . . . 7 


\section{SUMMARY}

The flow rate and the metallurgical condition of a frit vent from a simulant-fueled clad vent set (CVS) that had been hot isostatically pressed (HIP) for the Sixty-Watt Heat Source program were evaluated. The flow rate from the defueled vent cup subassembly was reduced approximately $25 \%$ from the original flow rate. No obstructions were found to account for the reduced flow rate. Measurements indicate that the frit vent powder thickness was reduced about $30 \%$. Most likely, the powder was compressed during the HIP operation, which increased the density of the powder layer and thus reduced the flow rate of the assembly. All other observed manufacturing attributes appeared to be normal, but the vent hole activation technique needs further refinement before it is used in applications requiring maximum CVS integrity. 


\section{INTRODUCTION}

Clad vent set (CVS) 9808-00-2322 was shipped from Lockheed Martin Energy Systems, Inc. (Energy Systems) for use with the Sixty-Watt Heat Source (SWHS) program. It was loaded at Los Alamos National Laboratory (LANL) with a simulant fuel (depleted urania) pellet and identified as SC 6029 (S/N 13). The CVS units for the SWHS program were hot isostatically pressed (HIP) at $1000^{\circ} \mathrm{C}$ using a pressure of 3500 psig for $1 \mathrm{~h}$. The purpose of the HIP operation was to minimize the gaps between the iridium alloy CVS and the fuel pellet. This minimization was intended both to reduce the potential for producing fuel fines caused by vibrational effects and to improve the impact response by making the fueled CVS more like a monolithic body with a ductile skin.

The fueled (either with plutonia or urania simulant fuel) CVSs were sent to EG\&G-Mound Applied Technologies, Inc. (EG\&G-MAT) for additional assembly and substoichiometric reduction of the plutonia. To reduce the fuel stoichiometry, a hole was drilled through the flattened (from HIP operation) decontamination cover to activate the vent hole. This hole-drilling operation was also done on SC 6029 . Subsequently, SC 6029 was returned from EG\&G-MAT to LANL where it was cut open, the simulant fuel was removed, and the CVS was decontaminated for follow-up evaluation at Energy Systems. A description of this evaluation and the results follow. 


\section{PROCEDURE}

The cylindrical section of the vent cup subassembly portion (9753-00-1597) of SC 6029 was parted carefully from the bottom section, which included the frit vent assembly (9752-00-3480) and the centerdrilled decontamination cover (3619-00-6239). Then the bottom section was flow tested five times using the CVS production flow test apparatus. After flow testing, the decontamination cover/cup/frit vent section was removed using a wire-fed electrical discharge machine (EDM) and machined into two parts. The largest part contained the entire vent hole (fully visible through EG\&G-MAT's drilled area) so that the cross section of the vent hole region could be evaluated metallographically. Metallographic preparation of this part was done per the standard CVS metallographic procedure, placing the cross-sectional plane of examination near the center of the vent hole. Photographs were taken at various magnifications in both the as-polished and the etched conditions in numerous areas of the part cross section. Thickness measurements of the decontamination cover, backing disc, cover disc, and powder were made using the $100 \mathrm{X}$ and $400 \mathrm{X}$ magnification photographs. Photographs at these magnifications were used because they offered the best resolution at the component edges. 


\section{RESULTS AND DISCUSSION}

The original flow rate for the vent cup subassembly was $5.6 \mathrm{~cm}^{3} / \mathrm{min}$. The flow rate is required to be between 4.5 and $7.5 \mathrm{~cm}^{3} / \mathrm{min}$ for flight-quality CVS units. After it was returned to Energy Systems, prepared, and remeasured, the flow rate (average \pm one standard deviation) was $4.16 \pm 0.030 \mathrm{~cm}^{3} / \mathrm{min}$. Metallographic evaluation revealed no obstructions or foreign material that would account for the reduced flow rate (see Figs. 1 through 5). The original thickness of the frit vent subassembly was $0.40 \mathrm{~mm}$. The original thicknesses of each of the frit vent subassembly components, backing disc, cover disc, and powder were calculated to be approximately equal at $0.133 \mathrm{~mm}$. Measuring the component thicknesses in Fig. 4 shows that the backing disc and cover disc thicknesses have remained the same. However, Figs. 4 and 5 show that the powder layer thickness has been reduced to approximately $0.092 \mathrm{~mm}$, or about $30 \%$ from the original thickness of $0.133 \mathrm{~mm}$.

The HIP operation likely is responsible for compressing the frit vent powder and reducing the flow rate. During manufacture of the frit vents, they are routinely compressed mechanically after the diffusion bonding operation to reduce the flow rate to within the specified limits. The frit vents are compressed at room temperature - usually twice using a pressure of about 1500 psig for a nearly instantaneous duration. Thus, it is plausible that the application of $3500 \mathrm{psig}$ at $1000^{\circ} \mathrm{C}$ for $1 \mathrm{~h}$ on the outside of a simulant-fueled CVS would result in measurable compression and densification of the frit vent powder.

A number of manufacturing observations can be made by examining Figs. 1-6. First, the differences in grain sizes between the decontamination cover heat treated at $1250^{\circ} \mathrm{C}$, the cup heat treated at $1375^{\circ} \mathrm{C}$, and the backing disc and cover disc exposed to the sintering and diffusion bonding treatments at $1500^{\circ} \mathrm{C}$ and $1900^{\circ} \mathrm{C}$, respectively, are contrasted in Figs. 1 through 3 and Fig. 6 . Figs. 1 and 2 show that the holedrilling operation actually went through twice the thickness of the decontamination cover by going about $0.127 \mathrm{~mm}$, or a fifth of the way through the wall of the 0.66- mm-thick cup. Fig. 3 shows that the vent hole EDM operation produces machining artifacts on the order of $0.09 \mathrm{~mm}$ deep. Figs. 4 and 5 show good bonding both between frit vent powder particles and between particles and foil components. Finally, Fig. 6 shows good weld integrity for both the decontamination cover-to-cup weld and the frit vent-to-cup weld. As expected, no interaction occurs between these welds. All of these observed manufacturing attributes appeared to be normal. However, in applications that require the full integrity of the iridium alloy CVS, the vent hole should not be activated using the hole-drilling technique or the technique must be refined further so that the cup is not encroached. 


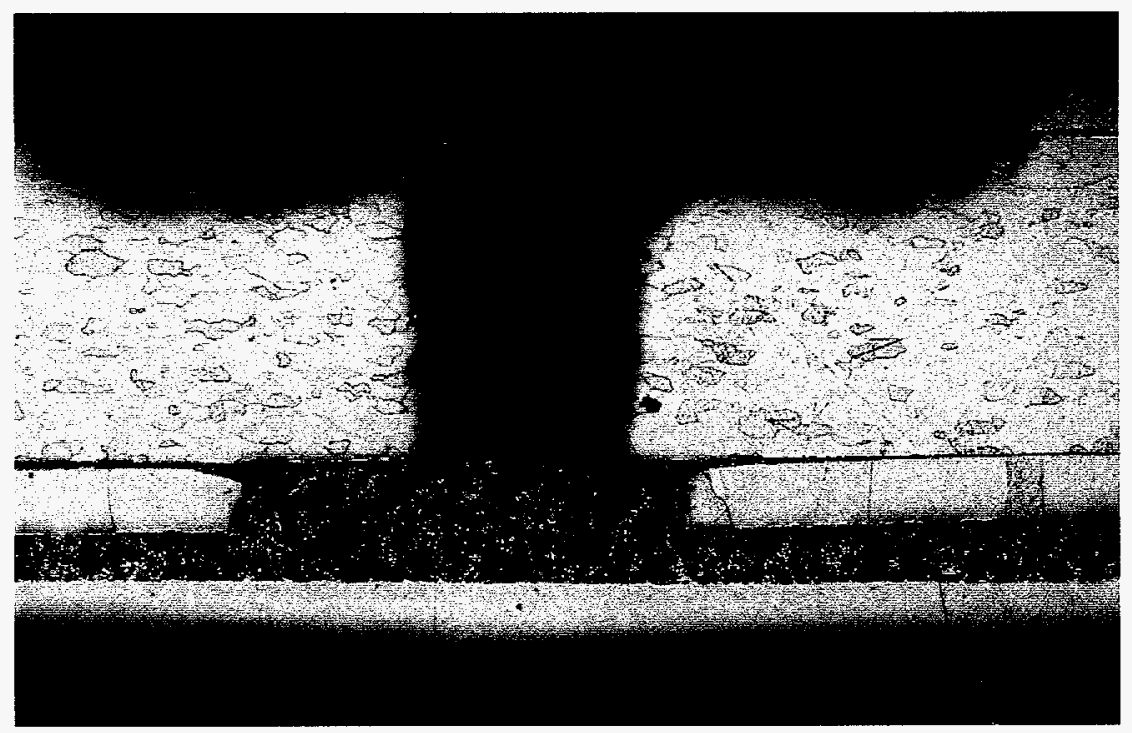

Fig. 1. Vent hole region of SC 6209 after HIP and hole-drilling operations. Part (not drilled) of decontamination cover is seen at top right. Cup with vent hole and wide drilled region (above vent hole) is below decontamination cover. Below the cup is the frit vent backing disc and powder with the cover disc at the bottom of the photograph (etched -50X).

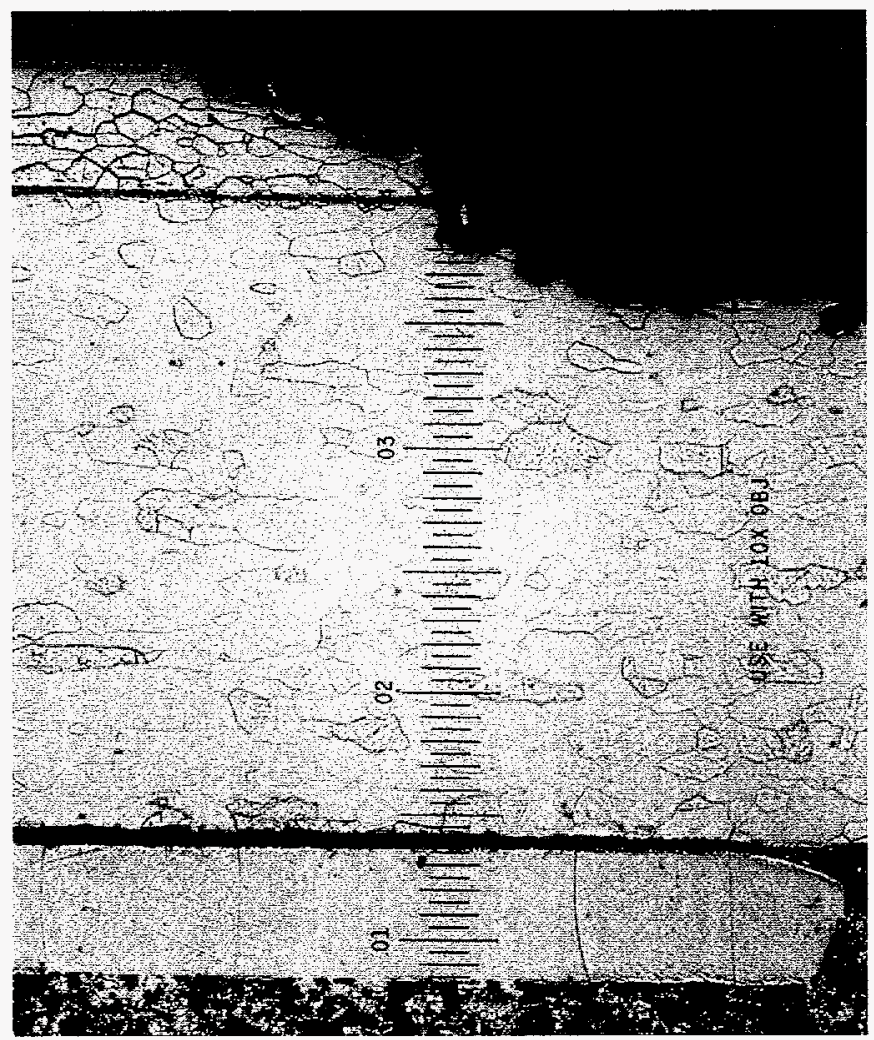

Fig. 2. Left of vent hole region shown in Fig. 1. Decontamination cover at top, followed by cup, frit vent backing disc, and powder at bottom. Drilled region is at top right (etched $-100 \mathrm{X}$ ). 


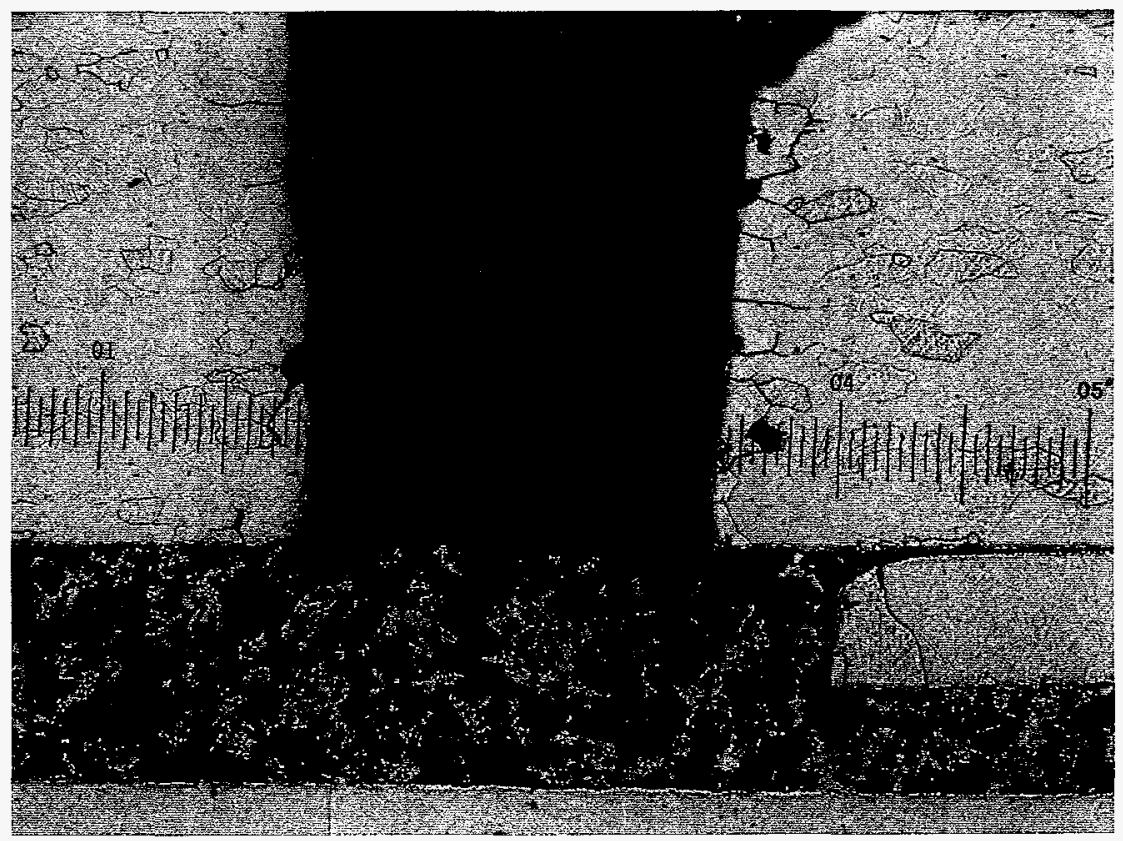

Fig. 3. Vent hole region showing EM artifacts (etched - 100X).

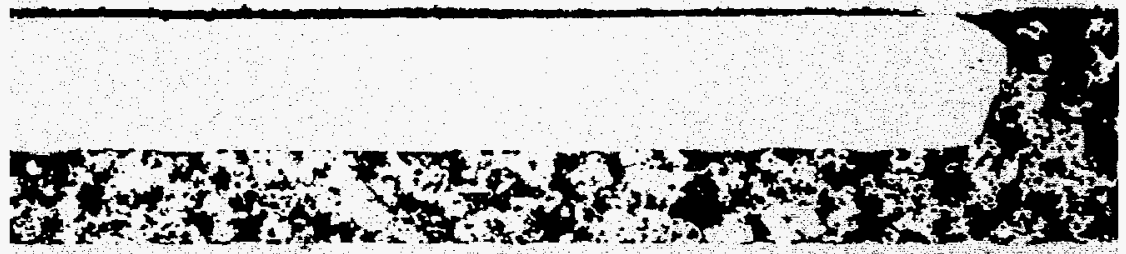

Fig. 4. Frit vent subassembly showing good particle-to-particle and particle-to-foil component bonding. Frit vent backing disc hole is visible on the right side (as polished $\mathbf{- 1 0 0 X}$ ). 


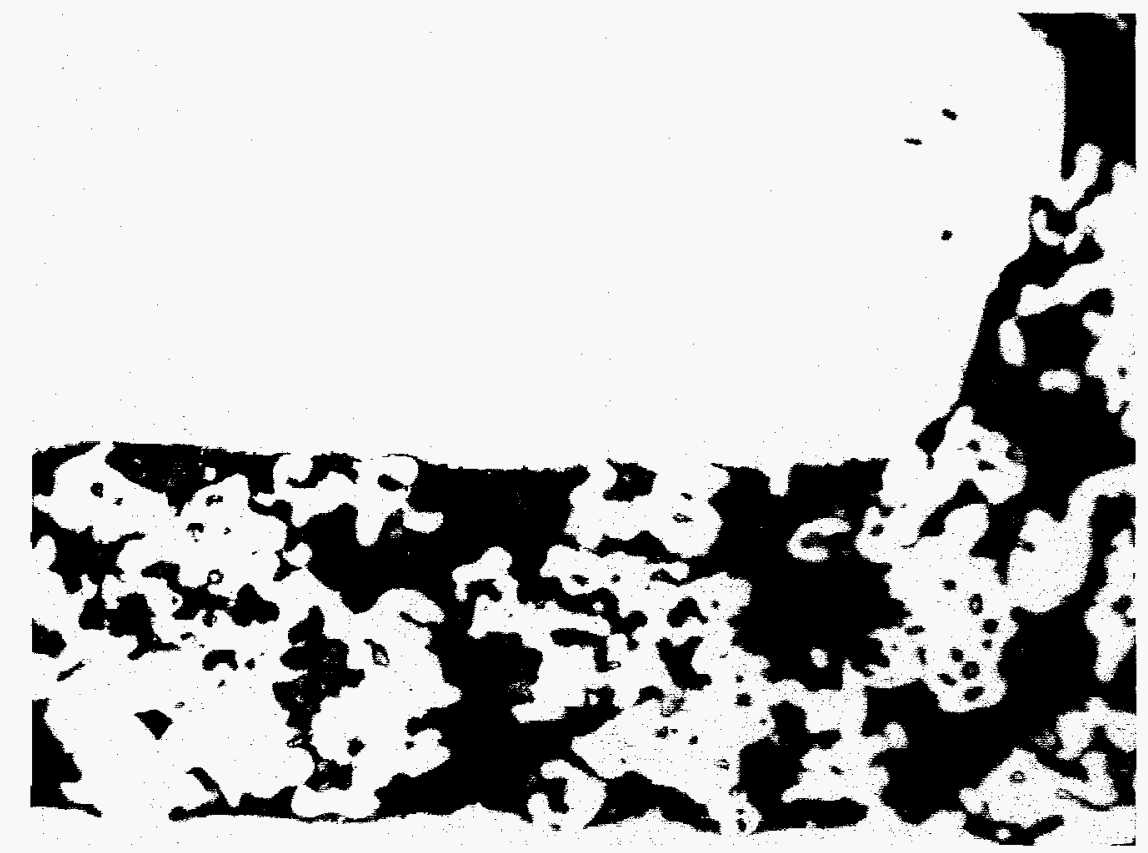

Fig. 5. Higher-magnification view of Fig. 4 with frit vent backing disc at top, backing disc hole at right, and cover disc at the very bottom (as polished $-400 \mathrm{X}$ ).

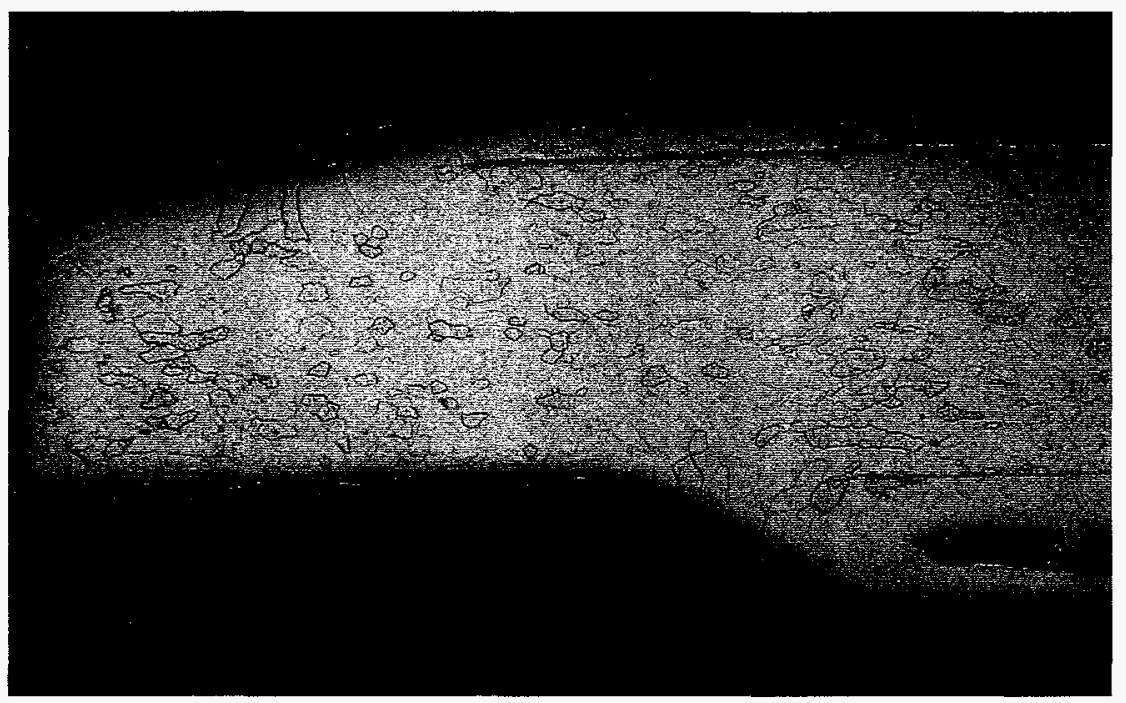

Fig. 6. Decontamination cover-to-cup (upper left) and frit vent-to-cup (lower right) weld regions (etched - 50X). 


\section{CONCLUSIONS}

The flow rate from the defueled vent cup subassembly was reduced approximately $25 \%$ from the original flow rate. No obstructions were found to account for the reduced flow rate. Measurements indicate that the frit vent powder thickness was reduced about $30 \%$. Most likely, the powder was compressed during the HIP operation, increasing the density of the powder layer and thus reducing the flow rate of the assembly. All of the observed manufacturing attributes appeared to be normal. However, the hole-drilling technique used to activate the vent hole encroached a fifth of the way into the vent cup wall. For applications requiring the full integrity of the iridium alloy CVS, this vent hole activation technique should not be used without further refinement. 


\section{Distribution}

\section{Department of Energy - Oak Ridge Operations}

P. Carpenter

R. A. Edlund

R. L. Lahti

S. R. Martin, Jr.

\section{Department of Energy - Office of Nuclear Energy, Science, and Technology}

W. J. Barnett

EG\&G-MAT, Inc.

D. M. Gabriel

F. A. Koehler

J. R. McDougal

Lamb Associates, Inc.

E. W. Johnson

\section{Los Alamos National Laboratory}

T. G. George

E. M. Foltyn

\section{Oak Ridge National Laboratory}

R. H. Cooper

J. F. King

E. K. Ohriner

J. P. Moore

\section{Oak Ridge Y-12 Plant}

H. W. Berry

K. J. Helle

A. K. Lee/DOE-OSTI (2)

T. M. Mustaleski, Jr.

W. G. Northcutt, Jr./E. L. Bird

W. T. Thomas

G. B. Ulrich (3)

Y-12 Central Files - RC 